\title{
The characteristics of synonymous codon usage in the initial and terminal translation regions of encephalomyocarditis virus
}

\author{
X.-X. MA, Y.-P. FENG, J.-L. LIU, Y.-Q. ZHAO, L. CHEN, P.-H. GUO, J.-Z. GUO, Z.-R. MA* \\ College of Life Science and Engineering, Northwest University for Nationalities, Lanzhou, 730030, P. R. China
}

Received July 2, 2013; accepted February 19, 2014

\begin{abstract}
Summary. - The synonymous codon usage patterns in the initial and terminal translation regions (ITR, TTR) of the whole coding sequence of encephalomyocarditis virus (EMCV) were analyzed in relation to those in its natural hosts using the sequences accessible in databases. In general, some low-usage host codons were found overrepresented in the ITR and TTR of the virus, while some high-usage host codons were found under-represented in the two viral regions. These relationships are thought to participate in the regulation of the speed of translation of viral proteins and in the suppression of ribosomal traffic jams, both aiming at the increase of virus yields.
\end{abstract}

Keywords: encephalomyocarditis virus; initial translation region; terminal translation region; synonymous codon usage

\section{Introduction}

The encephalomyocarditis virus (EMCV, the genus Cardiovirus of the family Picornaviridae) is an RNA virus with a worldwide distribution. This virus is a single-stranded positive-sense RNA virus with a genome of about $7.8 \mathrm{~kb}$, which consists of an open reading frame (ORF) flanked by two untranslated regions (UTR) at the 5 '- and 3 '-ends. The 5'-UTR comprises an internal ribosome entry site (IRES), from which viral protein translation is initiated in a capindependent manner (De Pietri Tonelli et al., 2003; Denis et al., 2006). The 3'-UTR terminates with an heterogeneous poly (A) tail involved in the binding of the viral RNA-dependent RNA polymerase, whose encoding gene is located upstream of the 3'-UTR (Cui et al., 1993). The two ends flanking ORF of EMCV play an important role in the translation of the polyprotein (Davies and Kaufman, 1992; Oudshoorn et al., 1990). During the course of translation of the polyprotein

*Corresponding author. E-mail: maxiaoxia956@163.com, mzr@ xbmu.edu.cn; phone: +86-931-2938311.

Abbreviations: EMCV = encephalomyocarditis virus; IRES = internal ribosome entry site; ITR = initial translation region; RSCU $=$ relative synonymous codon usage value; TTR $=$ terminal translation region; UTR = untranslated region of EMCV, the IRES controls binding of the $40 \mathrm{~S}$ ribosomal subunit to initiate this translation (Jackson and Kaminski, 1995; Kaminski et al., 1994). The influence of the UTR on the codon usage pattern of the ITR of a particular gene has been reported by previous studies (Zhou et al., 2010, 2013b,c). Although evolutionary studies generally suggest that the viral genes with efficient expression represent high codon adaptation in host cell environment, the precise fitness of viral genome associated with translationally adapted codons remains a topic of active debate (Kudla et al., 2009; Stanssens et al., 1986). Tuller et al. (2010) reported that both ITR and TTR play a role in the control of the gene expression at the late stage of translation initiation (Tuller et al., 2010). In order to investigate the potential effects of the synonymous codon usage of the hosts on the translation of EMCV proteins, we employed the codon usage bias, which is included in the synonymous codon usage data of the hosts (pig, human and mouse), to analyze the codon usage bias of EMCV ITR and TTR in relation to the whole coding sequence of EMCV.

\section{Materials and Methods}

The 16 ORFs of EMCV were downloaded from the National Center for Biotechnology Information (NCBI) (http://www.ncbi. 
nlm.nih.gov/Genbank/). The accession numbers are: AF356822, DQ464062, DQ464063, FJ604852, FJ604853, FJ897755, HM641897, DQ517424, EU780148, EU780149, DQ288856, X87335, AY296731, M37588, M22457, and X74312.

To investigate the synonymous codon usage bias of the ITR and TTR of the EMCV ORF, we employed multiple sequence alignments performed with the Clustal W (1.7) computer programs. To analyze the relationship of the codon usage between EMCV and its natural hosts, the synonymous codon usage frequencies of domestic pig, human and mouse were obtained from the codon usage database http://www.kazusa.or.jp/codon/ (Nakamura et al., 2000), and the synonymous codon usage data for EMCV and the three hosts were calculated as "relative synonymous codon usage value" (RSCU) by following formula (Sharp et al., 1986):

$$
R S C U=\frac{g_{i j}}{\sum_{j}^{n_{i}} g_{i j}} \cdot n_{i}
$$

where $g_{i j}$ is the observed number of the the $j^{\text {th }}$ codon for the $i^{\text {th }}$ amino acid (which has $n_{i}$ synonymous codons). The RSCU data were used to evaluate the difference of the synonymous codon usage between EMCV and its hosts.

In order to identify the usage bias of the 59 synonymous codons, it was arbitrary set that codons with RSCU values $>1.6$ were regarded as over-represented, while codons with RSCU values $<0.6$ were considered under-represented (Wong et al., 2010; Zhou et al., 2013a). Therefore, a synonymous codon with RSCU value $<0.6$ or $>1.6$ can be defined as a biased one in this study. In a comparison of the synonymous codon usage pattern between the virus and the hosts, if both RSCU values for a specific codon of the virus and that of the corresponding codon for host are in the same range (i.e. less than 0.6 or more than 1.6 or between 0.6 and 1.6), this pattern will be considered to be a similar codon usage pattern. In this study, a group of codons, whose RSCU values ranged from 0.6 to 1.6 needed to be defined again, namely, when both RSCU value of EMCV and that of the hosts for the same codon range from 0.6 to 1.0 or from 1.0 to 1.6 , the usage pattern of the specific codon between the virus and the host is considered to be similar.

To calculate the codon usage preference $(R)$ in synonymous codon usage between the target contexts and the whole coding sequence of EMCV, we developed a simple method based on a previous report (Zhou et al., 2011).

$$
R=\ln \left(\frac{n_{240} / N_{240}}{n / N}\right)
$$

where $n_{240}$ is the sum of a synonymous codon in the 240 codons comprising the ITR or TTR of EMCV, $N_{240}$ is the sum of the corresponding amino acids in the given region, $n$ is the sum of this synonymous codon in the whole coding sequence, $N$ is the sum of the corresponding amino acid in the whole coding sequence.

\section{Results}

The synonymous codon usage pattern between EMCV ORF and its hosts

As for the synonymous codon usage patterns of EMCV ORF, it is noted that some under-represented codons (UUA for Leu, UCG, AGU, AGC for Ser, CCG for Pro, ACG for Thr, GCG for Ala, and CGA for Arg) and only one overrepresented codon (AGA for Arg) were found in this virus ORF (Table 1). It is interesting that the degree of codon usage bias for four amino acids (Phe, Tyr, Glu, and Cys), which are each encoded by two synonymous codons, is relative small. The phenomena might serve as a genetic marker of EMCV. In addition, we found that the codons with $\mathrm{CpG}, \mathrm{CpC}$, and GpG dinucleotides are not over-represented in EMCV ORF (Table 1). This feature might to some degree enable this virus to replicate successfully. As for the codon usage pattern of EMCV and the three hosts, 21 out of 59 codons are similarly used (Table 1). It is noted that the four amino acids (Phe, His, Asn, and Asp), which are each encoded by two synonymous codons, have a reversed tendency to be selected by EMCV and the three hosts (Table 1). Among the under-represented codons mentioned above, the synonymous codon usage patterns of UUA, UCG, CCG, ACG, and GCG in EMCV ORF are similar with the corresponding ones of the hosts (Table 1). This result may suggest that the translation selection of the hosts plays an important role in the formation of the synonymous codon usage of this virus.

\section{The codon usage bias for the ITR and TTR of EMCV}

The relationships between the synonymous codon usage data for pig, human and mouse and codon usage bias for the ITR and TTR of EMCV, respectively, were analyzed. It is interesting that the usage bias for some synonymous codons (all synonymous codons for Phe, Gln, Asn and Asp, UUA, CUU, CUC, and CUG for Leu, AUU for Ile, GUU, GUC and GUA for Val, UCA, UCG and AGC for Ser, CCC, CCA and CCG for Pro, ACC and ACG for Thr, GCC and GCG for Ala, CGU, CGC, CGA and AGA for Arg, GGU, GGA and GGG for Gly) was similar for both of the two target regions, since the codon usage preference $(\mathrm{R})$ values of these codons in the two target regions are similar (both more than 0 or less than 0) (Table 2). Some codons (CUG for Leu, AGC for Ser, ACC for Thr, GCC for Ala, and CAG for Gln), which are rarely used by the three hosts, have a strong tendency to exist in the two target regions (Fig. 1-2; Tables 1 and 2). As 
(a)

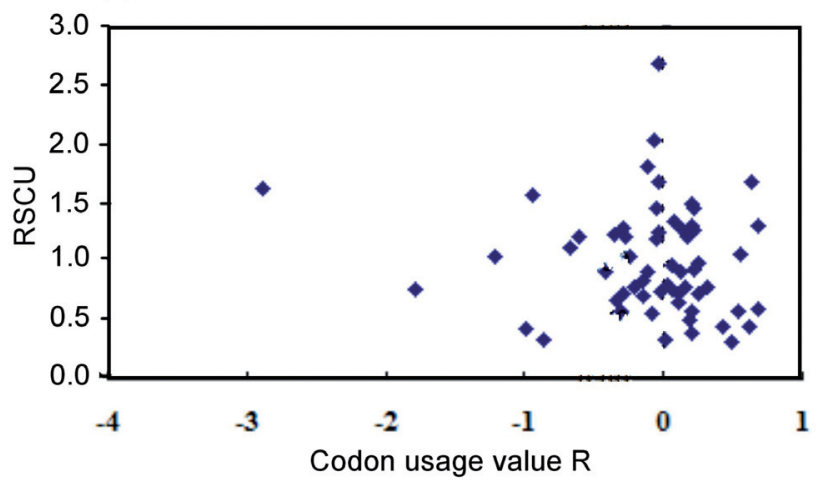

(b)

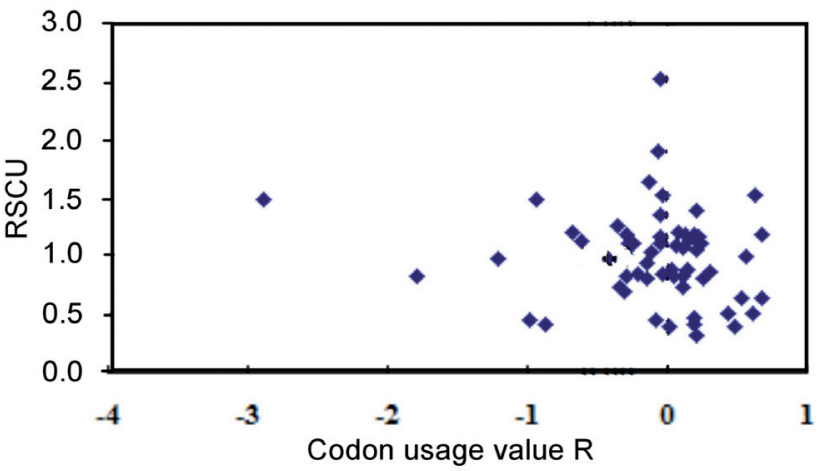

(c)

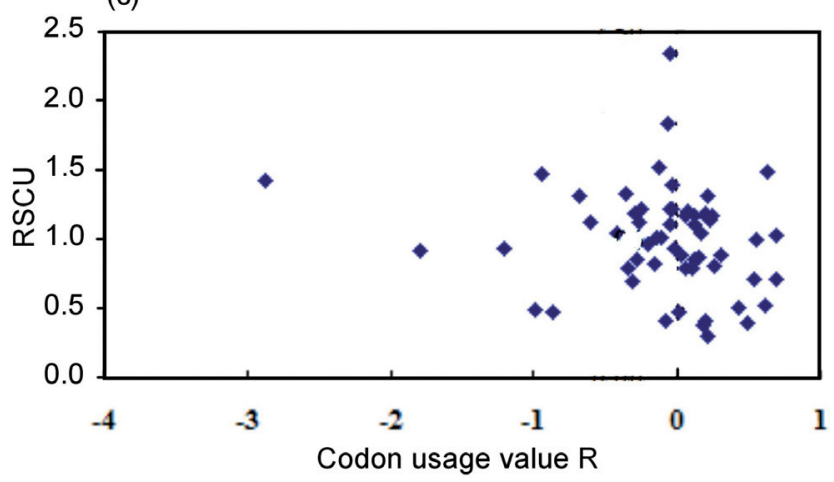

Fig. 1

The relationship between the synonymous codon usage (RSCU values) for the hosts and the codon usage preference ( $R$ values) for the EMCV ITR

(a) The relationship between the synonymous codon usage for pig and the codon usage for EMCV ITR; (b) the relationship between the synonymous codon usage for human and the codon usage for EMCV ITR; (c) the relationship between the synonymous codon usage for mouse and the codon usage for EMCV ITR. The R values indicate the difference of usage bias for synonymous codon between the regions of interest compared to the entire coding region of EMCV RNA.
Table 1. RSCU values for total sequences of EMCV and its natural hosts

\begin{tabular}{|c|c|c|c|c|}
\hline $\begin{array}{c}\text { Codons } \\
\text { (amino acids) }\end{array}$ & EMCV & Pig & Mouse & Human \\
\hline UUU(F) & 1.11 & 0.79 & 0.88 & 0.87 \\
\hline UUC(F) & 0.89 & 1.21 & 1.12 & 1.13 \\
\hline UUA(L) & $0.45 \downarrow$ & $0.32 \downarrow$ & $0.40 \downarrow$ & $0.39 \downarrow$ \\
\hline UUG(L) & 1.43 & 0.67 & 0.79 & 0.73 \\
\hline CUU(L) & 0.96 & 0.65 & 0.79 & 0.73 \\
\hline CUC(L) & 0.99 & 1.35 & 1.20 & 1.21 \\
\hline CUA(L) & 0.77 & $0.33 \downarrow$ & $0.48 \downarrow$ & $0.40 \downarrow$ \\
\hline CUG(L) & 1.41 & $2.68 \uparrow$ & $2.34 \uparrow$ & $2.53 \uparrow$ \\
\hline AUU(I) & 1.56 & 0.91 & 1.02 & 1.03 \\
\hline AUC(I) & 0.70 & $1.67 \uparrow$ & 1.49 & 1.52 \\
\hline AUA(I) & 0.73 & $0.42 \downarrow$ & $0.49 \downarrow$ & $0.44 \downarrow$ \\
\hline GUU(V) & 0.92 & $0.57 \downarrow$ & 0.69 & 0.69 \\
\hline GUC(V) & 0.95 & 1.07 & 1.00 & 1.00 \\
\hline GUA(V) & 0.64 & $0.34 \downarrow$ & $0.48 \downarrow$ & $0.42 \downarrow$ \\
\hline GUG(V) & 1.49 & $2.03 \uparrow$ & $1.84 \uparrow$ & $1.90 \uparrow$ \\
\hline $\mathrm{UCU}(\mathrm{S})$ & 1.54 & 0.99 & 1.18 & 1.11 \\
\hline UCC(S) & 1.32 & 1.50 & 1.31 & 1.39 \\
\hline UCA(S) & 1.43 & 0.73 & 0.86 & 0.84 \\
\hline UCG(S) & $0.54 \downarrow$ & $0.39 \downarrow$ & $0.30 \downarrow$ & $0.33 \downarrow$ \\
\hline AGU(S) & $0.59 \downarrow$ & 0.77 & 0.92 & 0.84 \\
\hline $\operatorname{AGC}(S)$ & $0.58 \downarrow$ & $1.62 \uparrow$ & 1.43 & 1.50 \\
\hline $\mathrm{CCU}(\mathrm{P})$ & 1.06 & 1.05 & 1.22 & 1.12 \\
\hline $\mathrm{CCC}(\mathrm{P})$ & 1.11 & 1.46 & 1.21 & 1.35 \\
\hline $\mathrm{CCA}(\mathrm{P})$ & 1.33 & 0.94 & 1.15 & 1.07 \\
\hline CCG(P) & $0.50 \downarrow$ & $0.56 \downarrow$ & $0.41 \downarrow$ & $0.46 \downarrow$ \\
\hline $\mathrm{ACU}(\mathrm{T})$ & 1.26 & 0.83 & 1.01 & 0.94 \\
\hline $\mathrm{ACC}(\mathrm{T})$ & 1.28 & $1.68 \uparrow$ & 1.40 & 1.52 \\
\hline $\operatorname{ACA}(\mathrm{T})$ & 1.14 & 0.92 & 1.18 & 1.07 \\
\hline ACG $(\mathrm{T})$ & $0.32 \downarrow$ & $0.57 \downarrow$ & $0.41 \downarrow$ & $0.46 \downarrow$ \\
\hline GCU(A) & 1.21 & 0.96 & 1.17 & 1.09 \\
\hline GCC(A) & 1.44 & $1.80 \uparrow$ & 1.52 & $1.64 \uparrow$ \\
\hline GCA(A) & 0.84 & 0.74 & 0.93 & 0.85 \\
\hline GCG(A) & $0.52 \downarrow$ & $0.50 \downarrow$ & $0.38 \downarrow$ & $0.42 \downarrow$ \\
\hline UAU(Y) & 1.01 & 0.73 & 0.86 & 0.84 \\
\hline $\mathrm{UAC}(\mathrm{Y})$ & 0.99 & 1.27 & 1.14 & 1.16 \\
\hline $\mathrm{CAU}(\mathrm{H})$ & 1.22 & 0.70 & 0.82 & 0.81 \\
\hline $\mathrm{CAC}(\mathrm{H})$ & 0.78 & 1.30 & 1.18 & 1.19 \\
\hline $\mathrm{CAA}(\mathrm{Q})$ & 0.83 & $0.44 \downarrow$ & $0.52 \downarrow$ & $0.51 \downarrow$ \\
\hline CAG(Q) & 1.17 & 1.56 & 1.48 & 1.49 \\
\hline $\operatorname{AAU}(\mathrm{N})$ & 1.18 & 0.79 & 0.87 & 0.89 \\
\hline $\operatorname{AAC}(\mathrm{N})$ & 0.82 & 1.21 & 1.13 & 1.11 \\
\hline $\mathrm{AAA}(\mathrm{K})$ & 0.85 & 0.76 & 0.79 & 0.82 \\
\hline AAG(K) & 1.15 & 1.24 & 1.21 & 1.18 \\
\hline GAU(D) & 1.18 & 0.80 & 0.89 & 0.89 \\
\hline GAC(D) & 0.82 & 1.20 & 1.11 & 1.11 \\
\hline GAA(E) & 0.93 & 0.72 & 0.81 & 0.81 \\
\hline GAG(E) & 1.07 & 1.28 & 1.19 & 1.19 \\
\hline UGU(C) & 0.99 & 0.79 & 0.96 & 0.86 \\
\hline UGC(C) & 1.01 & 1.21 & 1.04 & 1.14 \\
\hline CGU(R) & 0.83 & $0.44 \downarrow$ & $0.51 \downarrow$ & $0.51 \downarrow$ \\
\hline CGC(R) & 0.69 & 1.31 & 1.02 & 1.20 \\
\hline CGA(R) & $0.34 \downarrow$ & $0.60 \downarrow$ & 0.72 & 0.63 \\
\hline CGG(R) & 0.62 & 1.29 & 1.11 & 1.20 \\
\hline AGA(R) & $2.52 \uparrow$ & 1.12 & 1.32 & 1.20 \\
\hline AGG(R) & 1.00 & 1.23 & 1.33 & 1.26 \\
\hline GGU(G) & 1.06 & $0.57 \downarrow$ & 0.71 & 0.64 \\
\hline GGC(G) & 0.91 & 1.46 & 1.31 & 1.40 \\
\hline GGA(G) & 1.26 & 0.91 & 1.04 & 0.98 \\
\hline GGG(G) & 0.77 & 1.05 & 0.94 & 0.98 \\
\hline
\end{tabular}

$(\uparrow)$ over-represented; $(\downarrow)=$ under-represented. 
Table 2. The $\mathrm{R}$ values for the initiation translation region and the terminal translation region of EMCV

\begin{tabular}{|c|c|c|}
\hline $\begin{array}{c}\text { Codon } \\
\text { (amino acids) } \\
\end{array}$ & $\begin{array}{c}\text { Initiation translation } \\
\text { region } \\
\end{array}$ & $\begin{array}{c}\text { Terminal translation } \\
\text { region } \\
\end{array}$ \\
\hline UUU(F) & 0.31 & 0.21 \\
\hline UUC(F) & -0.61 & -0.33 \\
\hline UUA(L) & 0.49 & 0.23 \\
\hline UUG(L) & -0.34 & 0.06 \\
\hline CUU(L) & 0.11 & 0.11 \\
\hline CUC(L) & 0.08 & 0.20 \\
\hline CUA(L) & 0.01 & -0.25 \\
\hline CUG(L) & -0.04 & -0.30 \\
\hline AUU(I) & -0.11 & -0.41 \\
\hline AUC(I) & 0.64 & -0.52 \\
\hline AUA(I) & -0.98 & 0.75 \\
\hline GUU(V) & -0.31 & -0.24 \\
\hline GUC(V) & 0.56 & 0.04 \\
\hline GUA(V) & -0.87 & -0.57 \\
\hline GUG(V) & -0.06 & 0.26 \\
\hline $\mathrm{UCU}(\mathrm{S})$ & 0.25 & -0.32 \\
\hline $\mathrm{UCC}(\mathrm{S})$ & 0.21 & -0.86 \\
\hline $\mathrm{UCA}(\mathrm{S})$ & 0.12 & 0.37 \\
\hline UCG(S) & 0.21 & 0.82 \\
\hline AGU(S) & -1.79 & 0.07 \\
\hline AGC(S) & -2.88 & -0.37 \\
\hline $\mathrm{CCU}(\mathrm{P})$ & -0.25 & 0.15 \\
\hline $\mathrm{CCC}(\mathrm{P})$ & -0.04 & -0.33 \\
\hline $\mathrm{CCA}(\mathrm{P})$ & 0.21 & 0.31 \\
\hline $\mathrm{CCG}(\mathrm{P})$ & -0.08 & -1.15 \\
\hline $\operatorname{ACU}(\mathrm{T})$ & -0.14 & 0.33 \\
\hline $\mathrm{ACC}(\mathrm{T})$ & -0.04 & -0.02 \\
\hline $\mathrm{ACA}(\mathrm{T})$ & 0.12 & -0.53 \\
\hline ACG(T) & 0.20 & 0.04 \\
\hline GCU(A) & 0.06 & -1.00 \\
\hline GCC(A) & -0.12 & -0.16 \\
\hline $\mathrm{GCA}(\mathrm{A})$ & -0.03 & 0.53 \\
\hline GCG(A) & 0.19 & 0.56 \\
\hline UAU(Y) & -0.28 & 0.12 \\
\hline $\mathrm{UAC}(\mathrm{Y})$ & 0.22 & -0.14 \\
\hline $\mathrm{CAU}(\mathrm{H})$ & -0.15 & 0.50 \\
\hline $\mathrm{CAC}(\mathrm{H})$ & 0.20 & None \\
\hline $\mathrm{CAA}(\mathrm{Q})$ & 0.62 & 0.42 \\
\hline CAG(Q) & -0.94 & -0.46 \\
\hline $\operatorname{AAU}(\mathrm{N})$ & 0.15 & 0.13 \\
\hline $\mathrm{AAC}(\mathrm{N})$ & -0.27 & -0.23 \\
\hline $\operatorname{AAA}(\mathrm{K})$ & 0.05 & -0.04 \\
\hline $\mathrm{AAG}(\mathrm{K})$ & -0.04 & 0.03 \\
\hline GAU(D) & 0.03 & 0.26 \\
\hline GAC(D) & -0.05 & -0.56 \\
\hline $\mathrm{GAA}(\mathrm{E})$ & 0.25 & -0.25 \\
\hline GAG(E) & -0.29 & 0.18 \\
\hline UGU(C) & -0.21 & 0.55 \\
\hline UGC(C) & 0.17 & -1.27 \\
\hline CGU(R) & 0.43 & 0.28 \\
\hline CGC(R) & 0.68 & 0.14 \\
\hline CGA(R) & 0.68 & 0.25 \\
\hline CGG(R) & 0.12 & -0.17 \\
\hline $\mathrm{AGA}(\mathrm{R})$ & -0.68 & -0.24 \\
\hline AGG(R) & -0.35 & 0.16 \\
\hline GGU(G) & 0.53 & 0.62 \\
\hline GGC(G) & 0.22 & -0.15 \\
\hline GGA(G) & -0.42 & -0.69 \\
\hline GGG(G) & -1.21 & -0.22 \\
\hline
\end{tabular}

(a)

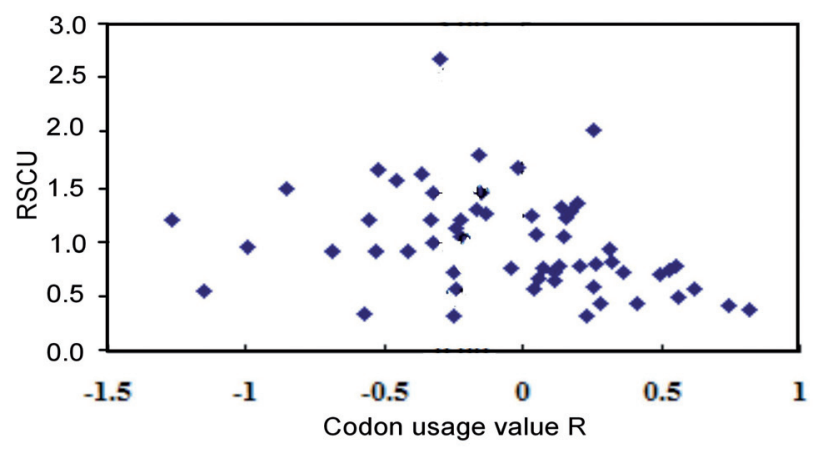

(b)

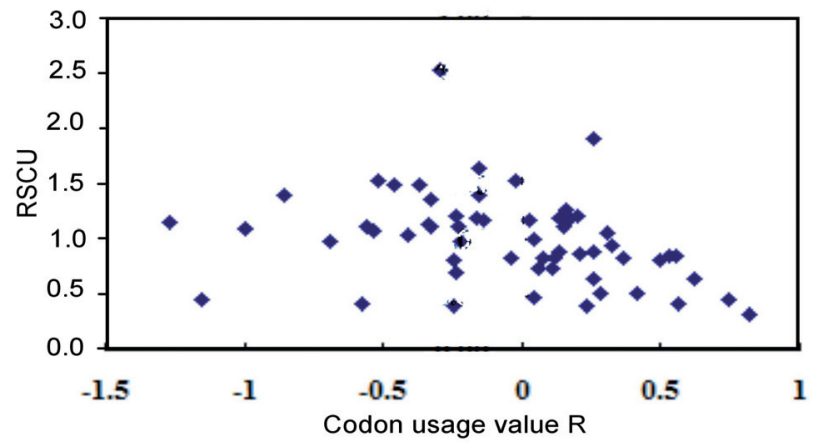

(c)

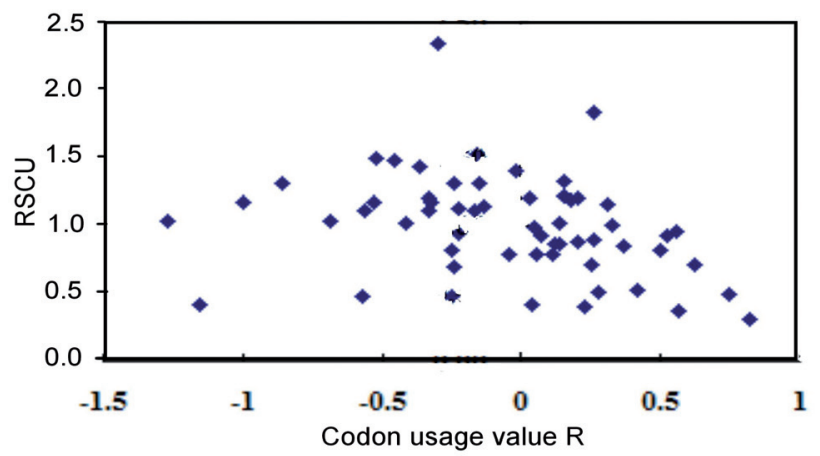

Fig. 2

The relationship between the synonymous codon usage (RSCU values) for the hosts and the codon usage preference ( $R$ values) for the EMCV ITR

(a) The relationship between the synonymous codon usage for pig and the codon usage for EMCV TTR; (b) the relationship between the synonymous codon usage for human and the codon usage for EMCV TTR; (c) the relationship between the synonymous codon usage for mouse and the codon usage for EMCV TTR. The R values indicate the difference of usage bias for synonymous codon between the regions of interest compared to the entire coding region of EMCV RNA. 
for the under-represented codons of its hosts, UUA, CUA, UCG, ACG, GCG, CAA, CGU, CGA, and GGU have a strong tendency to exist in the EMCV ITR, and UUA, AUA, UCG, ACG, GCG, CAA, CGU, CGA, and GGU have a strong tendency to exist in the EMCV TTR (Tables 1 and 2). As for the over-represented codons of the hosts, CUG, GUG, ACC, and GCC have a slight tendency to exist in the EMCV ITR, and CUG, AGC, ACC and GCC have a slight tendency to exist in the EMCV TTR. These results suggest that the usage patterns of codons existing in the two target regions play a role in the translational regulation of EMCV ORF.

\section{Discussion}

Viruses are ubiquitous cellular parasites and have a strong tendency to replicate and evolve rapidly. In this study, we found that some synonymous codon usage patterns of EMCV are similar with those of the three hosts (human, pig and mouse). This genetic characteristic may assist this virus to adapt to the cellular environment of the host and replicate in the host (Bahir et al., 2009; Welch et al., 2009). More specifically, the adaptation refers to the usage of the highly abundant tRNAs within the host cell by the virus, which would be optimal when the codon usage of the virus matches with that of the host. In order to maximize the translation speed of viral protein synthesis, the viral production impairs the immune response inside virus-infected cells, otherwise a large amount of non-preferred codons highly selected in viral genes could lead to low yield of viral proteins (Dupas et al., 2003; Sanchez et al., 2003). It is clear that the property of high stacking energy can effectively impair viral genome replication and transcription. EMCV has no obvious tendency to select the codons with $\mathrm{CpG}, \mathrm{CpC}$, and GpG dinucleotide. This characteristic may help the virus to reduce stacking energy of ORF and perform viral genome replication and transcription quickly.

The codon usage pattern plays an important role in controlling the gene expression (Parmley and Huynen, 2009; Rocha, 2004; Rosano and Ceccarelli, 2009). The purpose of this study was to explore the potential influence of the synonymous codon usage pattern of the hosts on the EMCV ITR and TTR. The distribution of the low-usage codons in a message is a major factor impacting the translation rate and the distribution of ribosomes on that message, and lowusage codon clusters are much more effective in blocking ribosome movement on the message than the dispersed low-usage codons (Zhang et al., 1994). The rare codons close to the initiator may stall the ribosome and prevent the entry of new incoming ribosomes (Chen and Inouye, 1994). The low-usage codons of the hosts, which are highly selected by the EMCV ITR and TTR, might influence the ribosome scanning. Some previous reports pointed out that the synonymous codon usage of the translation initiation region in the gene can play an important role in regulating the translation elongation efficiency (Rocha, 2004; Varenne et al., 1984).

Acknowledgements. This study were supported by the grant (No. 12XB37) from the University's Scientific Fund for the middle-aged and young scientists supported by the Northwest University for Nationalities and the grant (No. 31160033) from the National Natural Science foundation of China and the grant (ZYZ2012067) from the Fundamental Research Funds for the Central Universities deriving from the Northwest University for Nationalities.

\section{Reference}

Bahir I, Fromer M, Prat Y, Linial M (2009): Viral adaptation to host: a proteome-based analysis of codon usage and amino acid preferences. Mol. Syst. Biol. 5, 311. http://dx.doi. org/10.1038/msb.2009.71

Chen GT, Inouye M (1994): Role of the AGA/AGG codons, the rarest codons in global gene expression in Escherichia coli. Genes Dev. 8, 2641-2652. http://dx.doi.org/10.1101/ gad.8.21.2641

Cui T, Sankar S, Porter AG (1993): Binding of encephalomyocarditis virus RNA polymerase to the 3 '-noncoding region of the viral RNA is specific and requires the 3 '-poly(A) tail. J. Biol. Chem. 268, 26093-26098.

Davies MV, Kaufman RJ (1992): Internal translation initiation in the design of improved expression vectors. Curr. Opin. Biotechnol. 3, 512-517. http://dx.doi.org/10.1016/09581669(92)90079-X

De Pietri Tonelli D, Mihailovich M, Schnurbus R, Pesole G, Grohovaz F, Zacchetti D (2003): Translational control of Scamper expression via a cell-specific internal ribosome entry site. Nucleic Acids Res. 31, 2508-2513. http://dx.doi. org/10.1093/nar/gkg357

Denis P, Liebig HD, Nowotny N, Billinis C, Papadopoulos O, O'Hara RS, Knowles NJ, Koenen F (2006): Genetic variability of encephalomyocarditis virus (EMCV) isolates. Vet. Microbiol. 113, 1-12. http://dx.doi.org/10.1016/j. vetmic.2005.10.032

Dupas S, Turnbull MW, Webb BA (2003): Diversifying selection in a parasitoid's symbiotic virus among genes involved in inhibiting host immunity. Immunogenetics 55, 351-361. http://dx.doi.org/10.1007/s00251-003-0595-4

Jackson RJ, Kaminski A (1995): Internal initiation of translation in eukaryotes: the picornavirus paradigm and beyond. RNA 1, 985-1000.

Kaminski A, Belsham GJ, Jackson RJ (1994): Translation of encephalomyocarditis virus RNA: parameters influencing the selection of the internal initiation site. EMBO J. 13, 1673-1681.

Kudla G, Murray AW, Tollervey D, Plotkin JB (2009): Codingsequence determinants of gene expression in Escherichia coli. Science 324, 255-258. http://dx.doi.org/10.1126/ science. 1170160 
Nakamura Y, Gojobori T, Ikemura T (2000): Codon usage tabulated from international DNA sequence databases: status for the year 2000. Nucleic Acids Res. 28, 292. http://dx.doi. org/10.1093/nar/28.1.292

Oudshoorn P, Thomas A, Scheper G, Voorma HO (1990): An initiation signal in the $5^{\prime}$ untranslated leader sequence of encephalomyocarditis virus RNA. Biochim. Biophys. Acta 1050, 124-128. http://dx.doi.org/10.1016/01674781(90)90152-R

Parmley JL, Huynen MA (2009): Clustering of codons with rare cognate tRNAs in human genes suggests an extra level of expression regulation. PLoS Genet. 5, e1000548. http:// dx.doi.org/10.1371/journal.pgen.1000548

Rocha EP (2004): Codon usage bias from tRNA's point of view: redundancy, specialization, and efficient decoding for translation optimization. Genome Res. 14, 2279-2286. http://dx.doi.org/10.1101/gr.2896904

Rosano GL, Ceccarelli EA (2009): Rare codon content affects the solubility of recombinant proteins in a codon biasadjusted Escherichia coli strain. Microb. Cell Fact 8, 41. http://dx.doi.org/10.1186/1475-2859-8-41

Sanchez G, Bosch A, Gomez-Mariano G, Domingo E, Pinto RM (2003): Evidence for quasispecies distributions in the human hepatitis A virus genome. Virology 315, 34-42. http://dx.doi.org/10.1016/S0042-6822(03)00483-5

Sharp PM, Tuohy TM, Mosurski KR (1986): Codon usage in yeast: cluster analysis clearly differentiates highly and lowly expressed genes. Nucleic Acids Res. 14, 5125-5143. http:// dx.doi.org/10.1093/nar/14.13.5125

Stanssens P, Remaut E, Fiers W (1986): Inefficient translation initiation causes premature transcription termination in the lacZ gene. Cell 44, 711-718. http://dx.doi. org/10.1016/0092-8674(86)90837-8

Tuller T, Carmi A, Vestsigian K, Navon S, Dorfan Y, Zaborske J, Pan T, Dahan O, Furman I, Pilpel Y (2010): An evolutionarily conserved mechanism for controlling the efficiency of protein translation. Cell 141, 344-354. http://dx.doi. org/10.1016/j.cell.2010.03.031

Varenne S, Buc J, Lloubes R, Lazdunski C (1984): Translation is a non-uniform process. Effect of tRNA availability on the rate of elongation of nascent polypeptide chains. J. Mol. Biol. 180, 549-576. http://dx.doi.org/10.1016/0022-2836(84) $90027-5$

Welch M, Villalobos A, Gustafsson C, Minshull J (2009): You're one in a googol: optimizing genes for protein expression. J. R. Soc. Interface (Suppl. 4) S467-476. http://dx.doi. org/10.1098/rsif.2008.0520.focus

Wong EH, Smith DK, Rabadan R, Peiris M, Poon LL (2010): Codon usage bias and the evolution of influenza A viruses. Codon Usage Biases of Influenza Virus. BMC Evol. Biol. 10, 253. http://dx.doi.org/10.1186/1471-2148-10-253

Zhang S, Goldman E, Zubay G (1994): Clustering of low usage codons and ribosome movement. J. Theor. Biol. 170, 339-354. http://dx.doi.org/10.1006/jtbi.1994.1196

Zhou JH, Gao ZL, Zhang J, Ding YZ, Stipkovits L, Szathmary S, Pejsak Z, Liu YS (2013a): The analysis of codon bias of foot-and-mouth disease virus and the adaptation of this virus to the hosts. Infect. Genet. Evol. 14C, 105-110. http://dx.doi.org/10.1016/j.meegid.2012.09.020

Zhou JH, Su JH, Chen HT, Zhang J, Ma LN, Ding YZ, Stipkovits L, Szathmary S, Pejsak Z, Liu YS (2013b): Clustering of low usage codons in the translation initiation region of hepatitis C virus. Infect. Genet. Evol. 18, 8-12. http:// dx.doi.org/10.1016/j.meegid.2013.03.043

Zhou JH, Zhang J, Chen HT, Ma LN, Ding YZ, Pejsak Z, Liu YS (2011): The codon usage model of the context flanking each cleavage site in the polyprotein of foot-and-mouth disease virus. Infect. Genet. Evol. 11, 1815-1819. http:// dx.doi.org/10.1016/j.meegid.2011.07.014

Zhou JH, Zhang J, Ding YZ, Chen HT, Ma LN, Liu YS (2010): Characteristics of codon usage bias in two regions downstream of the initiation codons of foot-and-mouth disease virus. Biosystems 101, 20-28. http://dx.doi.org/10.1016/j. biosystems.2010.04.001

Zhou JH, Zhang J, Sun DJ, Ma Q, Ma B, Pejsak Z, Chen, HT, Ma LN, Ding YZ, Liu YS (2013c): Potential roles of synonymous codon usage and tRNA concentration in hosts on the two initiation regions of foot-and-mouth disease virus RNA. Virus Res. 176, 298-302. http://dx.doi.org/10.1016/j. virusres.2013.06.006 